\section{Getting back to football after having a total hip replacement (twice)}

\author{
Martin Sinclair
}

When I was a young boy watching my Dad play football, I remember wanting to be just like him. I was delighted when I joined my first team but for one reason or another I got kicked out of the team. This might have been because of my disability-I have cerebral palsy so I'm not sure if it was because of that. I moved onto another team and never looked back from there as football is my life!

I am most proud of being able to play in the Paralympics at London 2012 for the Great Britain Cerebral Palsy football team, as well as playing in several major international tournaments for the England Cerebral Palsy team. It was a great experience for me to travel around the world doing what I love. Walking out in front of 80000 people at the opening ceremony of the London 2012 Paralympics is something that I will never forget. I always got goose bumps when the national anthems were sung!

I never thought that any of this would be possible when I first dislocated my hip at the age of 15 . I was going down a slide at the local park, and felt my hip 'pop'. I went straight to the hospital, but they said it was a pulled muscle so I was walking around on my painful hip for 2 weeks. Eventually I needed a wheelchair to move around as I wasn't able to walk on my leg.

Luckily enough I already had an appointment scheduled with a surgeon about my hand (as I needed an operation on that), and the surgeon realised that there was something wrong with my hip. He sent me for an X-ray and they saw that the ball and socket joint had become detached. It was really painful but I was glad that they had got to the bottom of it. They eventually told me that I had a slipped capital femoral epiphysis, and explained to me what that meant. I was still struggling to walk and because of my cerebral palsy, my muscle tone went up following my injury.

\section{IN AND OUT OF HOSPITAL FOR 8 YEARS}

This was the start of a long journey for me, and following this episode I was in

Correspondence to Mr Martin Sinclair, Saints Foundation, Southampton Football Club, Southampton S014 5FP, UK; msinclair@saintsfc.co.uk

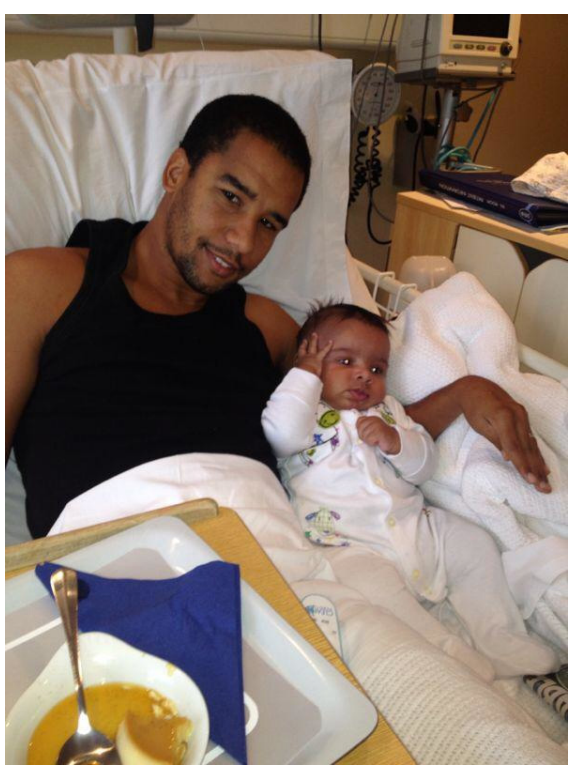

Figure 1 Immediately post-surgery with my son Harvey.

and out of hospital for around 8 years. After my hip replacement, I didn't know what to expect. I know the doctors said to me that very few people get back to sports like football after a hip replacement, and in fact they said that I could be putting myself at risk with things like dislocating my hip again after a bad challenge.

I believe that everyone is allowed an opinion and my opinion was that I wanted to return to football-for me that was the most important thing. I feel like my mindset was very important and I was determined that I was going to prove the doctor wrong and get back to what I love.

When I speak to other physios and doctors, they can't believe that I managed to get back to playing football with a hip replacement. It was a real challenge when I first had my hip replacement and the rehabilitation process was very hard. Learning how to walk again was difficult, and it was even harder learning how to run again. I had a major setback when I damaged my hip even further when I jumped off a cliff trying to save my friend a few years later, and that was a real low point. Luckily I had my family around me to help me with their positivity and without them I wouldn't have been able to get through the very long rehab process.
Because of my cerebral palsy, walking with crutches was really hard so I used a Zimmer frame to get about to start with. It was a real struggle. I also had another big setback a few years ago. I had nagging pain in my hip, and after an international football tournament the medical team ordered an X-ray for me which showed that I had needed another hip operation. This was almost 15 years on from my first hip replacement and I couldn't believe I had to go through all this again.

\section{BACK TO THE DRAWING BOARD}

I was fortunate to have a great surgeon, and the focus I had to return to football helped me get back to playing again sooner than I thought I would. In some ways the second operation was easier to handle as I knew what to expect after having the first one done. One big difference was that they wanted me to get up on my feet straight away and get going (figure 1), and that wasn't the case with my first operation as a teenager. I suppose technology and operations change over time.

The physiotherapists got me doing as much as I could early on-going up stairs, bed exercises, all that sort of stuff. It took me about 6 months to return to football following this second operation, and having the target of returning to a tournament in the summer to get fit for was a big motivation.

I haven't found many other younger athletes or players with a total hip or knee replacement, and hopefully if you are reading this and want to return to sport again after this type of operation then my story might help. I didn't want to be disrespectful to the doctors as I know they had my best interests at heart, but I feel like life is too short and I wanted to get back and do what I love which is play football.

My first game back when I was fit again was very emotional, I was so happy to have proved the doctors wrong and get back playing again. I had really missed being part of a team and the chat with everyone that you have as a squad, and it felt amazing to make my comeback. I did have fears before I put my first tackle in, but having put that to the back of my head I was able to push on and progress from there.

I hope that readers will learn that just because you have a new knee or a new hip, it doesn't mean that all your activities have to stop. I know that not many people with a hip or a knee replacement will want to play football, but I hope they will know that it was possible for me and that they can get back to some other form of sport to keep them happy and healthy. 


\section{Patient voices}

Three bits of advice for clinicians dealing with patients who have had a total hip replacement or total knee replacement

1. Everyone has opinions on their return to play goals-listen to the patient and try to see what means the most to him/her and what is really important.

2. Encourage the patient to surround him or herself with positive people. Whether it be family or friends, it will make all the difference to progress of rehabilitation.

3. Help the patient to develop a 'can do' rather than a 'can't do' mindset. Mindset is key!

\section{RELATED READING}

- Papalia R, Del Buono A, Zampogna $\mathrm{B}$, et al. Sport activity following joint arthroplasty: a systematic review. $\mathrm{Br}$ Med Bull 2012;101:81-103.

- Meira E, Zeni J. Sports participation following total hip arthroplasty. Int J Sports Phys Ther 2014;9: 839-850.

- Witjes S, Gouttebarge V, Kuijer P, et al. Return to sports and physical activity after total and unicondylar knee arthroplasty: a systematic review and meta-analysis. Sports Med 2016;46:269-292.

Contributors MS is the sole author of this piece.
Funding The authors have not declared a specific grant for this research from any funding agency in the public, commercial or not-for-profit sectors.

Competing interests None declared.

Patient consent for publication Not required.

Provenance and peer review Not commissioned: internally peer reviewed.

(c) Author(s) (or their employer(s)) 2019. No commercial re-use. See rights and permissions. Published by BMJ.

\section{Check for updates}

To cite Sinclair M. Br J Sports Med 2019;53:1321-1322.

Accepted 23 November 2018

Published Online First 11 December 2018

Br J Sports Med 2019;53:1321-1322. doi:10.1136/bjsports-2018-100249 